\title{
Revisions to User Costs for the Federal Reserve Bank of St. Louis Monetary Services Indices
}

\author{
Richard G. Anderson and Jason Buol
}

\begin{abstract}
This analysis discusses recent changes to the user cost figures that are computed as part of the Federal Reserve Bank of St. Louis monetary services indices (MSI). The authors first introduce an alternative splicing procedure, robust to differences in scale between series, for those price subindices which, individually, have a time span shorter than the overall MSI but are spliced to span the entire period. They then correct an error in the calculation of user costs for money market mutual funds that caused these funds' user costs to be based, for a considerable period of time, on the last-reported value for one input data series. Finally, the authors also restore the yield-curve adjustment for composite assets, which they removed from published data during 2004 as they explored the unusual behavior of the user cost data for small-denomination time deposits.
\end{abstract}

Federal Reserve Bank of St. Louis Review, November/December 2005, 87(6), pp. 735-49.

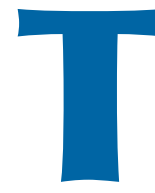

he Federal Reserve Bank of St. Louis has published monetary index numbers (often referred to as Divisia monetary aggregates) since the 1980s. In a set of papers, Anderson, Jones, and Nesmith (1997a,b,c) published a major revision and extension of the Federal Reserve Bank of St. Louis monetary services indices (MSI). A significant feature of that extension was new user costs for the MSI, based on an expanded collection of historical data and updated procedures for building user-cost index numbers.

Here, we discuss two recently implemented revisions to the MSI user costs:

- First, we introduce an alternative indexnumber splicing procedure. For some monetary assets, data are available to measure user costs only for intervals shorter than the interval of the overall index. In these cases, indices for the individual periods are spliced to create a user-cost measure that spans the quantity data's longer observation interval. In Anderson, Jones, and Nesmith (1997c), a geometric-mean formula (similar to the geometric mean used to create unilateral index numbers) is used to splice these subindices. At that time, the geometric mean formula produced (apparently) acceptable indices. During recent years, however, the scaling (normalization) in that method suggested to some users of the St. Louis MSI that small-denomination time deposits had negative own rates of return. Here, we replace that splicing method with a procedure proposed by Hill and Fox (1997), also based on geometric means. This primarily affects small time deposits.

- Second, we correct a programming error that caused one user cost-for money market

Richard G Anderson is an economist and vice president and Jason Buol, at the time this article was written, was a senior research analyst at the Federal Reserve Bank of St. Louis. Aeimit Lakdawala provided research assistance. The revisions discussed in this manuscript were included in published St. Louis MSI data beginning May 16, 2005. The authors thank the members of the St. Louis MSI Advisory Panel (William Barnett, Jane Binner, Adrian Fleissig, Barry Jones, and Travis Nesmith) for their comments on earlier drafts. All remaining errors and misunderstandings are our own. Views expressed are solely those of the authors, and not necessarily those of the Federal Reserve Bank of St. Louis, the Board of Governors of the Federal Reserve System, or their staff.

(C) 2005, The Federal Reserve Bank of St. Louis. Articles may be reprinted, reproduced, published, distributed, displayed, and transmitted in their entirety if copyright notice, author name(s), and full citation are included. Abstracts, synopses, and other derivative works may be made only with prior written permission of the Federal Reserve Bank of St. Louis. 


\section{Anderson and Buol}

mutual funds-to be based, for a considerable period of time, on the last-reported value for its own-rate input data series. We also improve, perhaps slightly, the accuracy of the MSI by introducing separate user costs for general-purpose/broker-dealer funds and institutional-type money market mutual funds.

In addition to the above, we also restore the yield curve adjustment to the calculation of user costs for composite assets; see the appendix for details. We removed the yield curve adjustment from the calculation of user costs during 2004 as we explored the causes of unusual behavior in the user costs for small time deposits. At that time, we were concerned that the yield curve adjustment, which assumes a common term premium in yields on Treasury securities and on banks' deposit offering rates, was distorting calculated user costs during periods when spreads between offering rates on short- and long-term deposits were near zero. Further investigation suggested this was not the case.

\section{UNILATERAL INDEX NUMBERS AND SPLICING TIME SERIES}

In an ideal world, index numbers would always be built from flawless sets of matching price and quantity data that span the complete desired time interval. In the real world, building index numbers requires methods to handle missing and/or incomplete data; two of the more common techniques used are unilateral index numbers and splicing.

A unilateral index number is an index number constructed from either price or quantity data, but not both-that is, an index number constructed in the absence of one type of data. Because quantity data are more expensive to collect than price data, available price data often are more detailed than corresponding quantity data. In such circumstances, it is desirable to combine the price data into an index that matches, in its level of aggregation, the available quantity data. Such indices are known as unilateral price indices (Diewert, 1995). ${ }^{1}$ In empirical studies, unilateral indices often arise in the case of "low-level" aggregation where the data are repeated observations in a panel-data structure-that is, repeated observations of a single product's price on different dates at, say, a number of retail outlets. Most often, quantity data-such as the quantity sold at each outletis not recorded. A common textbook example is the price of toothpaste, which often is collected at a large number of discount and drug stores without corresponding store-by-store sales data.

A distinctly different operation is splicing index numbers. Splicing is necessary when no single index number spans, in its date range, the entire desired time interval. (In most cases, length of the desired time interval is a judgment call by the researcher regarding the longest time span for which reasonably consistent indices can be constructed.) For monetary data, this typically happens when one data source or survey ends and a new one begins, perhaps with an overlap of several periods.

For the MSI user costs, Anderson, Jones, and Nesmith (1997c) built unilateral index numbers for a number of assets, including small time deposits, eurodollars, and repurchase agreements. Their discussion did not separate, however, the construction of unilateral price indices when all the components are defined over a common time span from the splicing of shorter, individual price indices. The primary focus of this analysis is to examine circumstance in which this decision matters importantly for interpreting the indices.

\section{Unilateral Index Numbers}

As we noted above, a unilateral index number is an index constructed from either price or quantity data, but not both. Because these are economic index numbers, it is desirable that the index be interpretable within an economic aggregation or demand theory framework. To do so for unilateral price indices, certain assertions must be made regarding the properties of the demand

\footnotetext{
1 Readers are cautioned that the term "unilateral" has been used with alternative meanings in other discussions of index numbers. Barnett (2005), for example, uses the term, in a multi-country index number framework, to refer to an approach in which there exists a single representative agent who is indifferent to his country of residence. This is not our context here.
} 
functions for the unobserved quantity data. Unfortunately, because the quantity data are not observed, these assertions are untestable. In applied studies, there are two common alternative assertions: either that the goods have infinite cross-price elasticities (perfect substitutes in demand) or that they have unitary cross-price elasticities (constant expenditure on the goods included in the subaggregate). Anderson, Jones, and Nesmith (1997c) accept an argument advanced by Erwin Diewert (1974) that the latter is more reasonable, albeit less commonly made. An implication of this assumption is that the unilateral price indices should be constructed using a Jevonsstyle geometric mean method, in which the growth rate of the index equals the growth rate of the ratio of the current period's geometric mean divided by the geometric mean in the previous period.

To be specific, consider a unilateral price index created from own rates of return on two sets of assets. Let $\left\{r_{1, t}, \ldots, r_{M, t}\right\}$ be a vector of own rates observed on $m=1, \ldots, M$ assets during period $t$, and let $\left\{r_{1, t-1}, \ldots, r_{S, t-1}\right\}$ be a vector of own rates observed on $s=1, \ldots, S$ assets during period $t-1$, where $M$ need not be equal to $S$. The growth rate of the Jevons user-cost subindex for these assets is calculated as

$$
\pi_{t}=\pi_{t-1}\left(\frac{\prod_{m=1}^{M}\left(\pi_{m, t}\right)^{(1 / M)}}{\prod_{s=1}^{S}\left(\pi_{s, t-1}\right)^{(1 / S)}}\right) .
$$

The term $\pi_{m, t}$ is the real user cost of the monetary services received from monetary asset $m$ during period $t$,

$$
\pi_{m, t}=\frac{R_{t}-r_{m, t}}{1+R_{t}},
$$

where $r_{m, t}$ is the holding-period yield between periods $t$ and $t+1$ (interest being received at the end of the period) and $R_{t}$ is the holding-period yield on the benchmark asset (Barnett, 1978 and 1980). In monetary aggregation theory, the benchmark asset is defined to be an asset that (i) has zero default risk and (ii) furnishes no monetary (liquidity) services during the household's planning period. An asset is assumed to furnish no monetary services to a household during a specific period if the cost of converting the asset into medium-of-exchange during that period is prohibitive. In empirical studies, the holding-period yield on the benchmark asset often is proxied by the yield-to-maturity on a low-rated but investmentgrade corporate bond, such as a Baa bond. ${ }^{2}$

Markets for lower-grade investment bonds tend to be thin and, hence, the transaction cost for speedy sale of a Baa bond likely is so uncertain as to cause the household to rank the bond at the very bottom of its continuum of monetary assets. The assumption that the benchmark asset has no default risk (that is, that the benchmark rate is nonstochastic) may be relaxed; see Barnett, Liu, and Jensen (1997), Barnett and Serletis (2000, Chap. 12), and Barnett and $\mathrm{Wu}$ (2005).

It is important to note that equation (1) contains no terms to adjust the two price vectors, $\left\{r_{1, t}, \ldots, r_{M, t}\right\}$ and $\left\{r_{1, t-1}, \ldots, r_{S, t-1}\right\}$, for differences in their average levels. It is commonplace to assume when building unilateral price indices that differences in the levels among the component price series are negligible. When they are not, an adjustment for scale is necessary. Such adjustments are commonplace when splicing index numbers, the topic of our next section.

\section{Splicing}

Splicing index numbers is necessary when the length (time span) of the individual, component index numbers is shorter than the desired length for the overall, combined index number. The index numbers to be spliced might be of any type, including unilateral indices. This situation most often occurs when a data source or survey ends and a new one begins, perhaps with an overlap of several periods. Care must be exercised when the levels of the two data sources differ. The topic

\footnotetext{
2 A well-known logical conundrum arises when the yield curve is inverted, such that the holding-period yield on a short-term asset that furnishes monetary services is greater than the return on a long-term asset that does not furnish monetary services. In empirical studies—and in the St. Louis MSI — this is resolved by defining the "benchmark asset" to be the asset with the highest holding-period yield, regardless of market liquidity or time to maturity. Such practice sometimes is referred to as the "envelope approach" to defining the benchmark yield; see Barnett, Offenbacher, and Spindt (1981) and Hancock (2005a,b).
} 


\section{Anderson and Buol}

of splicing index numbers has been discussed by a number of authors:

If the overlapping parts of the original series differ by only a scalar multiple, then the splicing problem is trivial because the two series can be combined by merely rescaling one of the series. Such an occurrence is unlikely, however, unless the two series overlap by a single observation. (Hill and Fox, 1997, p. 387)

In practice two runs of annual index numbers may overlap by more than one year. There is then a choice: the runs may be spliced together in any one year or over an average of years in the overlap. There is generally no unique result of the application of the splicing technique. The method is empirical and approximate. (Allen, 1975, p. 32; quoted in Hill and Fox, 1997, p. 387)

Hill and Fox (1997) show that only the geometric mean, among the general class of symmetric means, generates a spliced series that is invariant to rebasing/rescaling of either of the original series (when appropriate scale factors are included). Hill and Fox consider splicing two time series, where one series begins in period 1 and ends in period $M+N,(N>1)$, and the second series begins in period $M+1$ and ends in period $M+N+L$.

Specifically, consider two index numbers that share $N>1$ overlapping periods: $x_{i},(i=1, \ldots$, $M+N)$, and $y_{j},(J=M+1, \ldots, M+N+L)$. Let the spliced index be denoted $(x \sim y)_{n}, n=1, \ldots, M+N$ $+L$. At the first and last overlap points, the relative scales of the two series are $\left(y_{M+1} / x_{M+1}\right)$ and $\left(y_{M+N} / x_{M+N}\right)$. Letting the geometric mean of $N$ arguments $a_{n}, n=1, \ldots, N$ be denoted as

$$
M\left(a_{1}, \ldots, a_{N}\right)=\prod_{n=1}^{N}\left(a_{n}\right)^{1 / N},
$$

Hill and Fox (1997) define the spliced series as

(3)

$$
\begin{aligned}
(x \sim y)_{n} & =A_{1} x_{n}, & & n=1, \ldots, M \\
& =M\left(x_{n}, y_{n}\right), & & n=M+1, \ldots, M+N \\
& =A_{2} y_{n}, & & n=M+N+1, \ldots, M+N+L,
\end{aligned}
$$

where $A_{1}=\left(1 / x_{M+1}\right) M\left(x_{M+1}, y_{M+1}\right)$ and $A_{2}=\left(1 / y_{M+N}\right) M\left(x_{M+N}, y_{M+N}\right)$.
Essentially, the Hill and Fox method is a scaled version of the Jevons geometric mean method. Rescaling index numbers is a common practice because many index numbers are unique only up to a linear transformation. Spliced index numbers created via equation (3) have this feature. In particular, the spliced index number may be rescaled further, if desired, by dividing all observations by $A_{1}, A_{2}$, or a linear combination of $A_{1}$ and $A_{2}$, perhaps to preserve the level of either the first or second input series. Hereafter, we will refer to $(x \sim y)$ as the un-normalized Hill-Fox index and to

$$
\frac{(x \sim y)}{A_{2}}
$$

as the $A_{2}$-normalized Hill-Fox index. For comparison, we also discuss the $A_{1}$-normalized HillFox index,

$$
\frac{(x \sim y)}{A_{1}} .
$$

When interpreting index numbers, it is important to note that splicing index numbers via the geometric mean method is a mathematically nonlinear and non-invertible transformation. In other words, the original series $\{x\}$ and $\{y\}$ cannot be recovered from the spliced series $(x \sim y)$ even if the ratios $A_{1}$ and $A_{2}$ are known.

In previous versions of the St. Louis MSI (Anderson, Jones, and Nesmith, 1997c), longer spliced indices for user costs were created from shorter component user cost indices in a two-step method. First, the Jevons geometric mean formula shown in equation (1) was used to splice the two component indices. Second, the spliced index number was divided by $A_{1}$, forcing the spliced index's value to equal the geometric mean of the two component indices for the earliest time period when both of the component indices had valid data. (This formula differs from the one used in the $A_{1}$-normalized Hill-Fox index because the factors $A_{1}$ and $A_{2}$ are not used in building the index prior to normalization.) When the component indices were of different magnitudes, this practice imparted some undesirable properties to the spliced index number. The most serious 


\section{Figure 1}

\section{Small Time Deposit User Costs, Jevons Method vs. Un-Normalized Hill-Fox Method (commercial bank seasonally adjusted monthly data, January 1959-December 2004)}
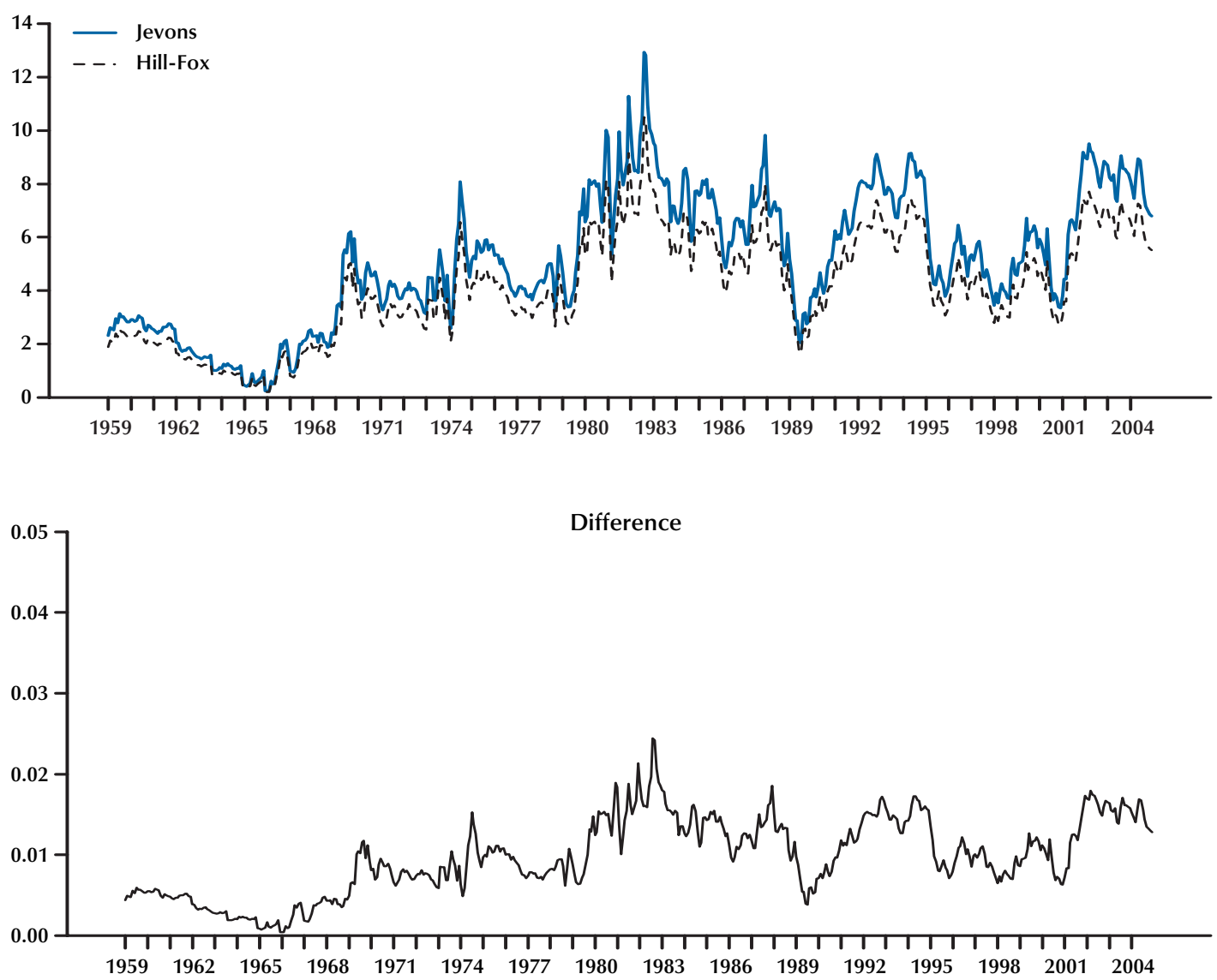

problems were for small time deposits, which we examine in the next section.

\section{USER COSTS FOR SMALL TIME DEPOSITS}

Creating index numbers for small time deposits is troublesome because of the lack of appropriate quantity data. For quantity data, only a single quantity is collected by the Federal Reserve-the total amount of small time deposit liabilities of depository institutions. No data are collected regarding either the original maturity or remaining time to maturity. For deposit offering rates, much more data are collected, including rates offered on new deposits for five maturities ( 7 to 91 days, 92 to 182 days, 183 days to 1 year, 1 year to 2.5 years, and 2.5 years or more). But, no data are collected on the distribution of actual rates being paid, and no data on the volume of new deposits issued at each rate. The challenge is to combine these data into accurate maturity-related user cost and quantity indices-an all-but-impossible task given the data limitations.

Data problems for small time deposits are further complicated by breaks in the data. From late 1983 (the demise of Regulation Q) through early 1997, the Board of Governors conducted a monthly survey known as the "Monthly Survey 
Figure 2

\section{Small Time Deposit User Costs, Jevons Method vs. Normalized Hill-Fox Method (commercial bank seasonally adjusted monthly data, January 1959-December 2004)}
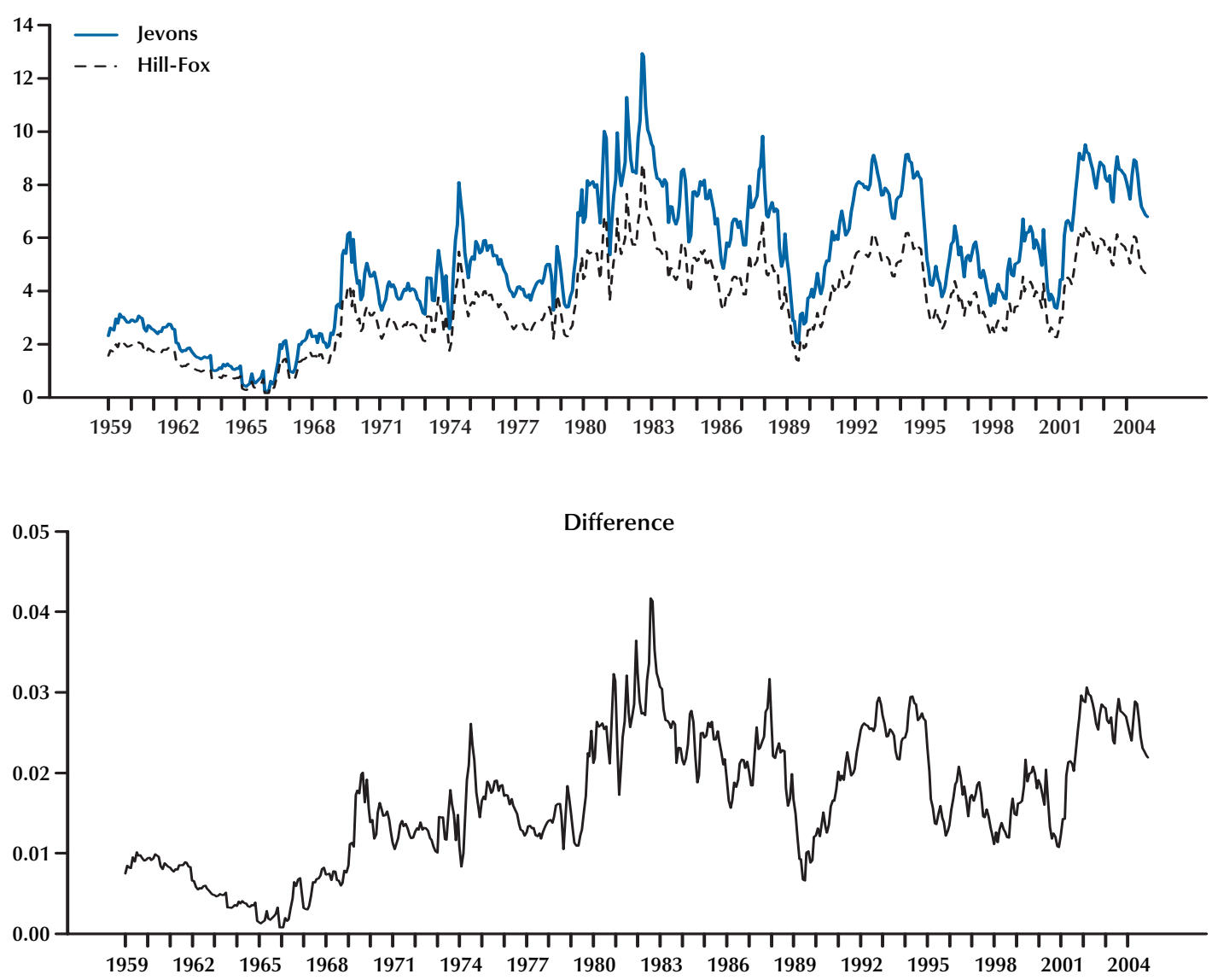

of Selected Deposits," or the FR2042 survey, to collect from approximately 500 larger banks offering rates on small time deposits. Questions asked on the survey varied somewhat through time. In our judgment, the changes were not so large as to invalidate the survey's time series for our purposes. The survey was discontinued and replaced in 1997 with survey data purchased from the Bank Rate Monitor Company; these data are available to us beginning in 1987. The Bank Rate Monitor survey includes a larger number of banks than the previous survey and, for the span of years when both are available, differs in level at times by as much as 200 basis points.

We measure the overall user cost of aggregate small time deposits at each date in each of the two data segments (corresponding to the FR2042 and Bank Rate Monitor surveys) using a Jevonsstyle geometric mean method for the user costs. The first step in its calculation is to "yield-curve adjust" the offering rates (own rates of return) on the five maturities of small time deposits by subtracting estimated maturity-specific liquidity premiums. (Details of the yield-curve adjustment are discussed in the appendix.) Next, user costs for each maturity and date, within each data segment, are calculated by subtracting the yieldcurve-adjusted own rates from the estimated benchmark rate. Finally, the two user-cost segments are spliced using the normalized Hill-Fox 


\section{Figure 3}

\section{Small Time Deposits at Banks, Own Rates Implied by Spliced User Costs (monthly data, January 1959-December 2004)}

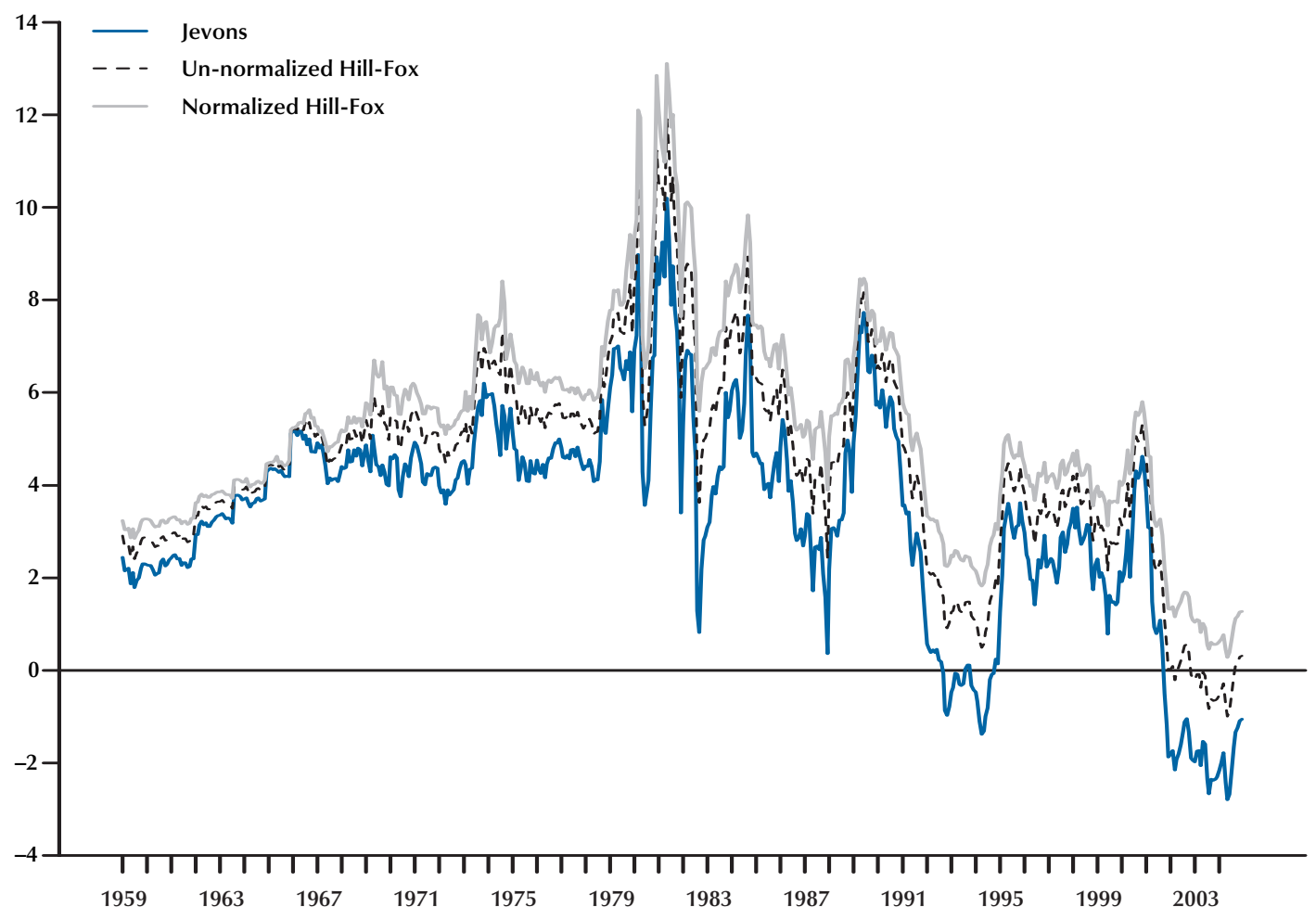

method-that is, the final user cost series is measured as equation (4). The two Hill-Fox scale factors, $A_{1}$ and $A_{2}$, are shown in Table 1 . We construct separate user cost indices for commercial banks and thrift institutions; here, we consider only the data for commercial banks. Data for thrifts are similar.

Figures 1 and 2 compare user costs for small time deposits constructed with three methods: the Jevons method, equation (1); the un-normalized Hill-Fox method, equation (3); and the $A_{2}$ normalized Hill-Fox method, equation (4). The un-normalized Hill-Fox values, shown in Figure 1, are consistently lower than, but quite close to, the values from the Jevons method. The values from the normalized Hill-Fox method, shown in Figure 2, are consistently lower than values from the un-normalized Hill-Fox method. The difference between the normalized and un-normalized
Table 1

\section{Splice Factors for Small Time Deposits in the Hill-Fox Method}

\begin{tabular}{lcc} 
& $\boldsymbol{A}_{\mathbf{1}}$ & $\boldsymbol{A}_{\mathbf{2}}$ \\
\hline Commercial banks & 0.811 & 1.19 \\
Thrift institutions & 0.775 & 1.24
\end{tabular}

values, algebraically, is due to division by the factor $A_{2}$; the information content of the two indices is the same.

Our preference for the normalized Hill-Fox index is based on the analysis shown in Figures 3 through 6.

Figure 3 illustrates our previous point that splicing index numbers via geometric means is 


\section{Figure 4}

\section{Small Time Deposit User Costs, Jevons Method and Components (commercial bank seasonally adjusted monthly data, January 1959-December 2004)}

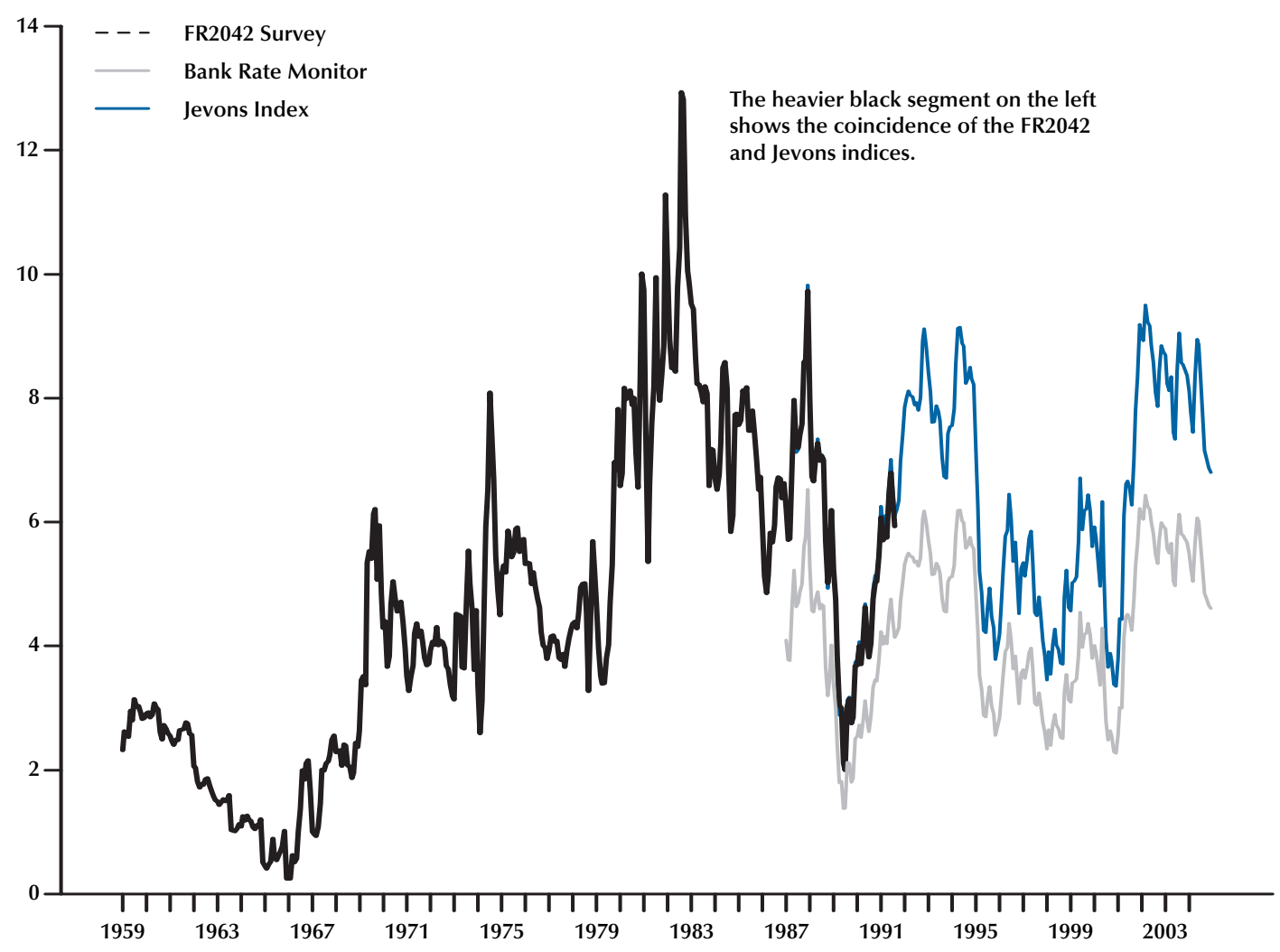

a nonlinear and non-invertible transformation. In this case, own rates of return for small time deposits cannot be recovered from spliced user costs by the familiar equation

(6) own rate $=$ benchmark rate - user cost.

The three lines in the figure correspond to own rates of return calculated with equation (6) from spliced user cost series constructed with three methods: our previous Jevons method; the unnormalized Hill-Fox method (equation (3)); and the $A_{2}$-normalized Hill-Fox method (equation (4)). For the Jevons method, calculated own rates of return are negative during the first half of the 1990s and after 2000. Some users of the MSI have calculated such negative own rates and called them to our attention as an error in the MSI con- struction; in fact, the negative values are an artifact from use of the Jevons method. For the unnormalized Hill-Fox method (equation (3)), the calculated own rates of return are negative, but less so, during 2003 and 2004. Own rates calculated with the $A_{2}$-normalized Hill-Fox method (equation (4)), are positive, although very close to zero during 2003.

The comparison shown in Figure 3 has disturbed some users of the MSI, who would prefer that own rates and user costs be invariant to the method used to construct the MSI and its components. Unfortunately, this is impossible, as is illustrated in Figures 4, 5, and 6. Each figure displays three index numbers. Two of the index numbers are the same on all three figures: a Jevons subindex built from the various maturity-specific 


\section{Figure 5}

\section{Small Time Deposit User Costs, Un-Normalized Hill-Fox Method and Components (commercial bank seasonally adjusted monthly data, January 1959-December 2004)}

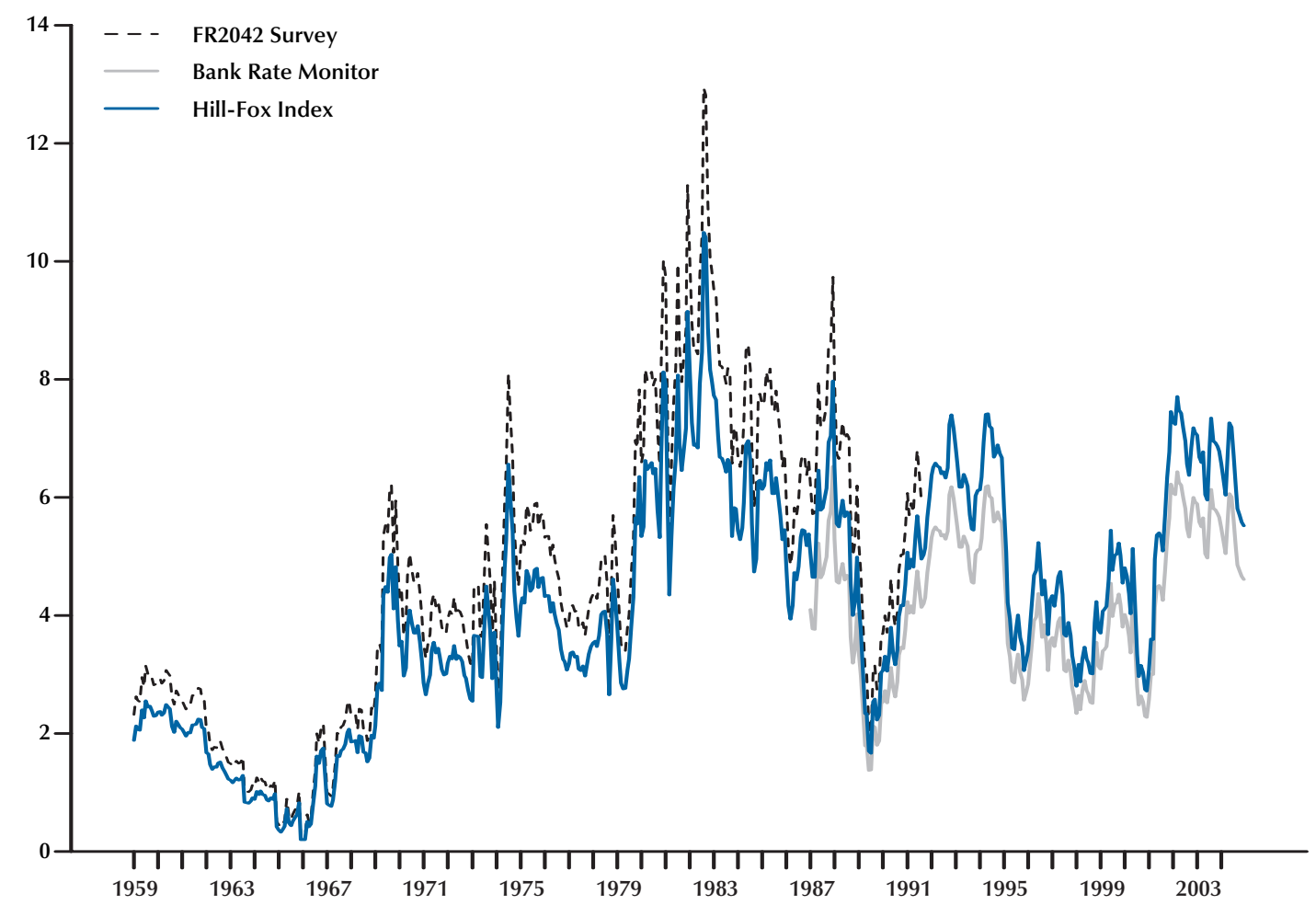

deposit offering rates collected on the FR2042 survey and a Jevons subindex built from similar data collected in the Bank Rate Monitor survey. The third index number in each figure corresponds to a method of splicing the FR2042 and Bank Rate Monitor index numbers.

- In Figure 4, the spliced index is the $A_{1^{-}}$ normalized Hill-Fox index, equation (5). As expected, the index tracks the FR2042 index prior to 1987. Beginning in 1987, the index follows the shape but not the level of the Bank Rate Monitor index.

- In Figure 5, the spliced index is the Hill-Fox (1997) index, equation (3). As expected, the Hill-Fox index lies below the FR2042 data prior to 1987 (the date corresponding to $A_{1}$ ), between the FR2042 and Bank Rate Monitor data from 1987 to 1997 (the date corresponding to $A_{2}$ ), and above the Bank Rate Monitor data after 1997.

- In Figure 6, the spliced index is the $A_{2}$ normalized Hill-Fox index, equation (4). As expected, the pattern is the opposite of Figure 4, with the normalized Hill-Fox index tracking the Bank Rate Monitor index after the end of the FR2042 index in 1997.

In the published, revised MSI user costs, we follow the method of Figure 6.

\section{MONEY MARKET MUTUAL FUND YIELD}

Money market mutual funds are an important asset in the MSI. In this revision, we both correct an error in the calculation of their user cost and introduce an extension. The error was the result 
Figure 6

\section{Small Time Deposit User Costs, Normalized Hill-Fox Method and Components (commercial bank seasonally adjusted monthly data, January 1959-December 2004)}

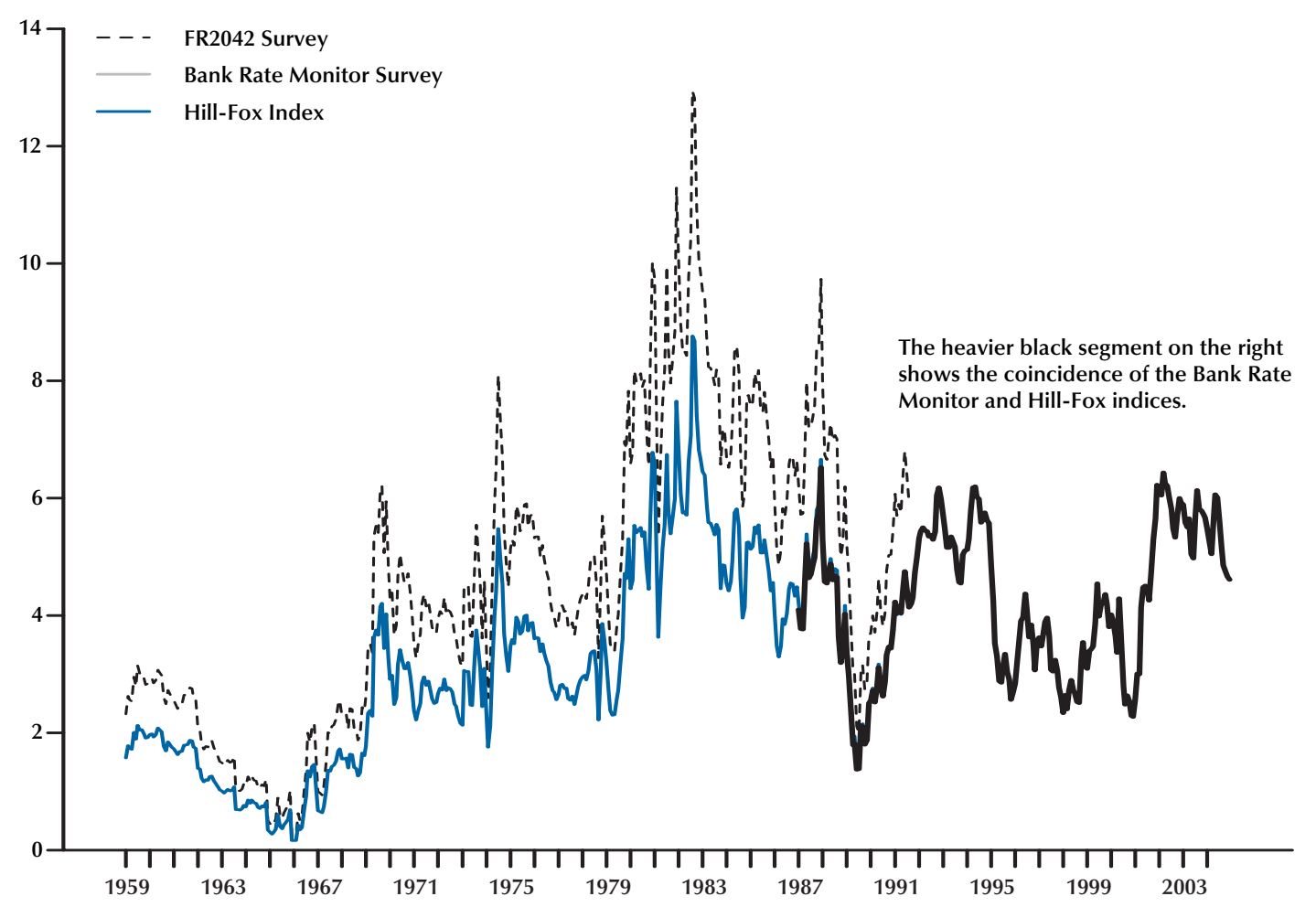

of an attempt gone awry to ensure timely publication even when the arrival of certain data was delayed. The extension improves the indices, beginning with data in 1997, by using separate own rates series for general-purpose/broker-dealer funds and institutionally oriented funds.

In their calculations, Anderson, Jones, and Nesmith (1997c) used unpublished data regarding the yield on money market mutual funds obtained from the Federal Reserve Board. Sometimes, tardy arrival of these data threatened to delay timely publication of the MSI figures even when other data had arrived. To minimize publication delays, when necessary and for one additional period, the last-reported figure was carried forward. This compromise was based on the assumption that any delayed observation would be in place by the following month's production date and, at that time, the correct observation would replace the temporary extrapolated value.

In April 1997, the data source for money market mutual funds changed. Unfortunately, due to an error, the last-reported figure from the previous database continued to be carried forward by the computer program. A sharp-eyed user of the MSI brought this error to our attention. We have since modified our procedures and programs such that replacement of a missing figure by extrapolation of the previous value cannot continue automatically for more than one additional month. This meets, in large part, the sometimes conflicting goals of producing high-quality data in a timely fashion even when receipt of some needed input figures is delayed.

The correct and incorrect figures for money market mutual fund yields during 1997-2003 are shown in Figure 7. The computer-generated incor- 


\section{Figure 7}

\section{Money Market Mutual Funds \\ (percent annual rate, not seasonally adjusted)}
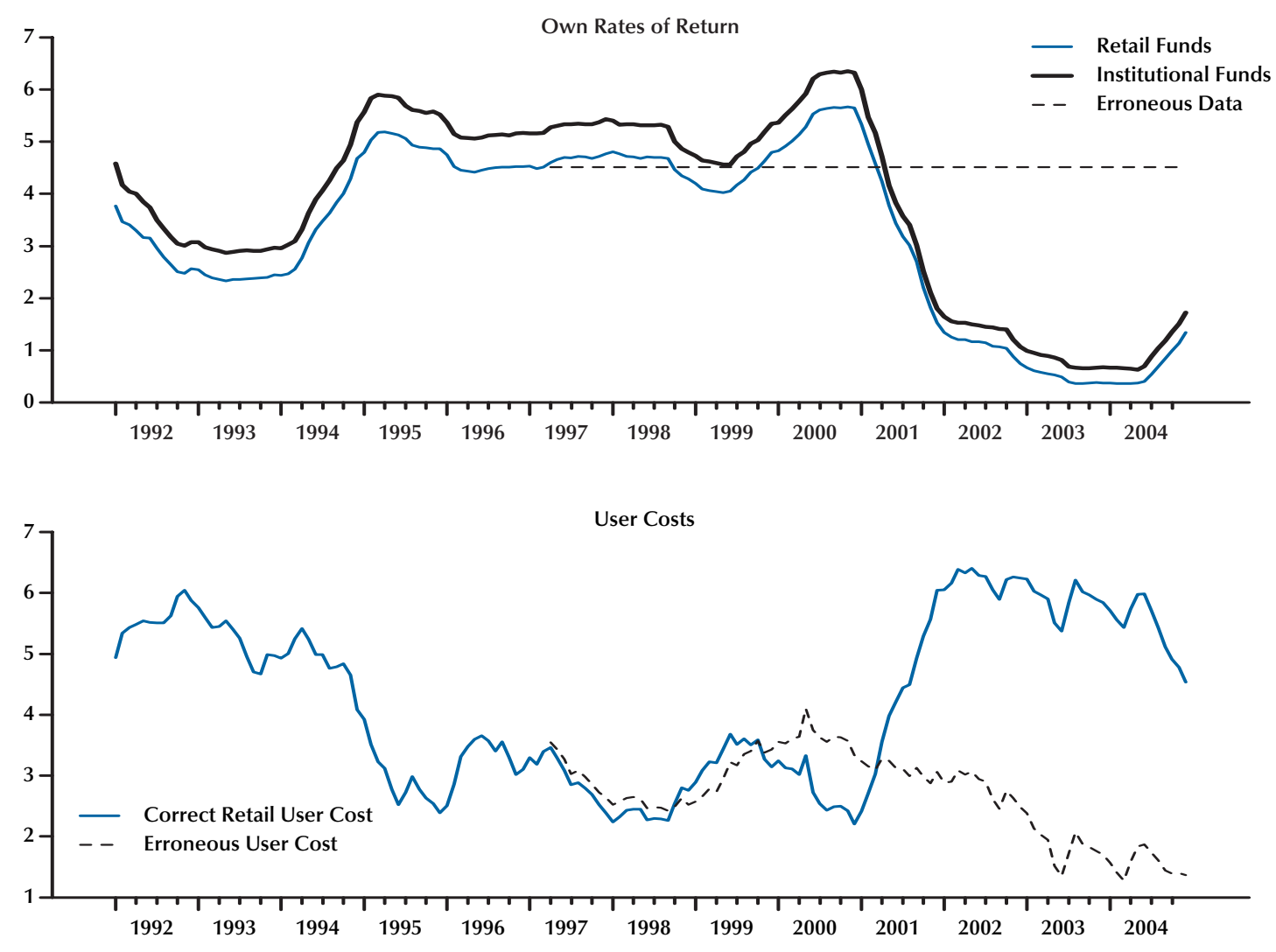

rect series (shown as the dotted line in Figure 7) shows no change after mid-1997, whereas the actual data, of course, have changed dramatically. In early 2004, for example, the average yield on broker-dealer money funds was approximately 1 percent, as opposed to 1997's nearly 5 percent yield. Assuming a benchmark yield of 5 percent, the difference in the user cost would be almost 4 percent (3.8 percent -0.06 percent).

\section{SUMMARY AND CONCLUSIONS}

Creating new index numbers by combining other index numbers is a common occurrence in applied research, and the geometric mean formula has well-known desirable properties for this pur- pose. In the St. Louis MSI, the geometric mean is used in two places: It is used to create unilateral index numbers for certain aggregate composite assets, and it is used to create certain longer indices by splicing shorter index numbers. In this analysis, we have emphasized that splicing indices differs in certain respects from the more general practice of creating a unilateral index number from a large number of component series. Building general unilateral indices usually entails combining a large number of component indices that exist for all dates and are of similar size. Splicing, however, usually entails creating a longer index from two shorter indices that are not defined over the complete time span but do overlap for a certain number of periods. In addition, the normalization differs. General unilateral indices have 


\section{Anderson and Buol}

no natural normalization-in the St. Louis MSI, they are normalized to their first period. Spliced series also have no natural normalization but, because their components often differ in scale, explicit adjustments for scale are included. (Similar to most index numbers, spliced indices may be renormalized to an arbitrary period without loss of information.) In the revised data presented herein, the spliced unilateral user-cost index for small time deposits is normalized to the latest time period in which both component indices are observed.

The use of index number theory to measure the amount of monetary services that consumers receive from their asset portfolio continues to be, after 25 years, an active subject of economic research. The Bank of England recently published revised series (Hancock, 2005a,b), and the European Central Bank is preparing new monetary index numbers for the euro area. For the United States, the only currently published monetary index number data are those of the Federal Reserve Bank of St. Louis. This analysis has introduced two changes to the St. Louis figures so as to improve the measured user costs of small time deposits and money market mutual funds.

\section{REFERENCES}

Allen, Roy G.D. Index Numbers in Theory and Practice. New York: Macmillan, 1975.

Anderson, Richard G. and Kenneth A. Kavajecz. "A Historical Perspective on the Federal Reserve's Monetary Aggregates: Definition, Construction, and Targeting." Federal Reserve Bank of St. Louis Review, March/April 1994, 76(2), pp. 1-31.

Anderson, Richard G.; Jones, Barry E. and Nesmith, Travis D. "Introduction to the St. Louis Monetary Services Index Project." Federal Reserve Bank of St. Louis Review, January/February 1997a, 79(1), pp. 25-29. Reprinted in Barnett and Serletis (2000).

Anderson, Richard G.; Jones, Barry E. and Nesmith, Travis D. "Monetary Aggregation Theory and Statistical Index Numbers." Federal Reserve Bank of St. Louis Review, January/February 1997b, 79(1), pp. 31-51.
Anderson, Richard G.; Jones, Barry E. and Nesmith, Travis D. "Building New Monetary Services Indices: Concepts, Data and Methods.” Federal Reserve Bank of St. Louis Review, January/February 1997c, 79(1), pp. 53-82.

Barnett, William A. "The User Cost of Money." Economics Letters, 1978, 1(2), pp. 145-49. Reprinted in Barnett and Serletis (2000).

Barnett, William A. "Economic Monetary Aggregates: An Application of Index Number and Aggregation Theory." Journal of Econometrics, 1980, 14(1), pp. 11-48. Reprinted in Barnett and Serletis (2000).

Barnett, William A.; Liu, Yi and Jensen, Mark "CAPM Risk Adjustment for Exact Aggregation Over Financial Assets." Macroeconomic Dynamics, 1997, 1(2), pp. 485-512.

Barnett, William A.; Offenbacher, Edward and Spindt, Paul. "New Concepts of Aggregated Money." Journal of Finance, May 1981, 36(2), pp. 497-505.

Barnett, William A. and Serletis, Apostolos. Theory of Monetary Aggregation. Amsterdam: North-Holland, 2000.

Barnett, William A. and Wu, Shu. "On User Costs of Risky Monetary Assets." Annals of Finance, January 2005, 1(1), pp. 35-50.

Cockerline, Jon P. and Murray, John D. "A Comparison of Alternative Methods of Monetary Aggregation: Some Preliminary Evidence.” Technical Report 28, Bank of Canada, November 1981.

Diewert, W. Erwin. "Intertemporal Consumer Theory and the Demand for Durables." Econometrica, May 1974, 42(3), pp. 497-516.

Diewert, W. Erwin. "Axiomatic and Economic Approaches to Elementary Price Indices.” NBER Working Paper 5104, National Bureau of Economic Research, May 1995.

Farr, Helen T. and Johnson, Deborah. "Revisions in the Monetary Services (Divisia) Indices of the Monetary Aggregates.” Staff Study 147, Federal Reserve Board of Governors, December 1985. 
Hancock, Matthew. "A New Measure of Divisia Money." Bank of England Monetary \& Financial Statistics, January 2005a, pp. 13-14.

Hancock, Matthew. "Divisia Money.” Bank of England Quarterly Bulletin, Spring 2005b, 45(1), pp. 39-46.
Hill, Robert J. and Fox, Kevin J. "Splicing Index Numbers." Journal of Business and Economic Statistics, July 1997, 15(3), pp. 387-89.

\section{APPENDIX}

\section{THE YIELD CURVE ADJUSTMENT FOR USER COSTS OF MONETARY ASSETS}

Certain aggregate assets included in the St. Louis MSI, such as small time deposits, are sums of individual components that differ by maturity; see Table A1. For these assets, maturity-specific own rates of return are available for the components, whereas maturity-specific quantities are not. The problem arises, then, regarding how to choose an own rate of return for such aggregated composite assets that is representative of the own rates of return on its components.

Choosing an own rate of return for a composite asset requires an economic assumption regarding its component assets' cross-price elasticities of substitution. In many studies, the components are assumed to be perfect substitutes. Under this assumption, the appropriate measure of the aggregate asset's own rate of return is the maximum of the components' own rates of return. We find this assumption implausible. Instead, the St. Louis MSI assumes that the components are imperfect substitutes for each other and that the entire group is separable in demand from other asset groups such that the household's total expenditure on the monetary services obtained from the asset group is invariant to changes in the relative own rates of return within the group. In this case, the appropriate measure of the aggregate asset's own rate is a Jevons-style geometric index number. Before the index can be calculated, however, maturity-related differences in the component assets' own rates of return must be removed by subtracting a yield curve adjustment. In the St. Louis MSI, the magnitude of the yield curve adjustment is equal to the slope of the Treasury constant-maturity yield curve between the appropriate maturities, if the slope is positive, or equal to zero, if the slope is negative (in other words, the yield curve is inverted). After subtracting the appropriate adjustment from each component's own rate of return, the composite asset's own rate of return is set equal to the maximum of the components' adjusted own rates of return. (All rates of return are stated as annualized, one-month holding-period yields on a bond interest, or 365-day, basis.)

The yield curve adjustment may be defined algebraically as follows (Anderson, Jones, and Nesmith, 1997c): Let $r_{n}$ be the own rate of return for a particular monetary asset and let $r_{n}^{T}$ be the yield-to-maturity (on a bond-equivalent basis) for a Treasury security, each having $n$ months to maturity. Let $r_{1}^{T}$ be the expected annualized one-month yield on Treasury bills, on a bond-equivalent basis. Then the yield curve-adjusted own rate is defined as

$$
r_{n}^{Y C A}=r_{n}-\max \left(r_{n}^{T}-r_{1}^{T}, 0\right) .
$$

For small time deposits, the effect of the yield curve adjustment on own rates of return for 1-, 2- and 3year maturities from January 1999 to December 2004 is shown in Figure 8. For earlier discussions of yield curve adjustment in the context of monetary index numbers, see Cockerline and Murray (1981) and Farr and Johnson (1985). 


\section{Table A1}

\section{Composite Monetary Assets in the MSI and Their Components}

\section{Composite monetary assets in the MSI and components}

\section{Eurodollars*}

Overnight, 3- and 6-month maturities

\section{Commercial paper ${ }^{\dagger}$}

3- and 6-month maturities

Bankers acceptances $^{\dagger}$

3- and 6-month maturities

\section{Large-denomination time deposits ${ }^{\ddagger}$}

3- and 6-month maturities

\section{Small-denomination time deposits $\$$}

7 to 91 day, 92 to 182 day, 183 day to 1 year, 1 to 2.5 year, and 2.5 year and longer maturities

\section{Relative importance as of January 2005 (billions of dollars, and share of total assets in MSI aggregate)}

\author{
$\$ 381$ billion (overnight and term); \\ 4 percent of MSI-M3
}

(Discontinued September 1998)

(Discontinued September 1998)

$\$ 1,116$ billion (negotiable and nonnegotiable); 11.8 percent of MSI-M3

\$826 billion; 12.9 percent of MS-M2; 8.7 percent of MSI-M3
Treasury yields used to calculate yield-curve adjustment

3- and 6-month secondary market Treasury bill rate

3- and 6-month secondary market Treasury bill rate

3- and 6-month secondary market Treasury bill rate

3- and 6-month secondary market Treasury bill rate

3- and 6-month secondary market Treasury bill rate; 1-, 2-, and 3-year Treasury constant-maturity yield

NOTE: * Eurodollars are included in the MSI-M3 index. This category includes overnight and term deposits. Federal Reserve data published through 1995 separated overnight from term deposits; data published thereafter does not. A primary reason for discontinuing the separate categories was that overnight deposits often were held under continuing contracts, thereby resembling term deposits, and term deposits often were withdrawable, thereby resembling overnight deposits. The St. Louis MSI use only total eurodollars.

${ }^{\dagger}$ Commercial paper and bankers acceptances are included in the MSI-L index. Calculation of this index was discontinued in September 1998 when certain required data became unavailable.

₹ Includes negotiable and nonnegotiable CDs. Separate figures for the two categories are not available.

$\S$ Includes "all-savers certificates," with variable ceiling rate and 12-month maturity. 


\section{Figure A1}

Yield Curve Adjustments for Small Time Deposits (adjusted rate $=$ offering rate - Treasury yield spread)
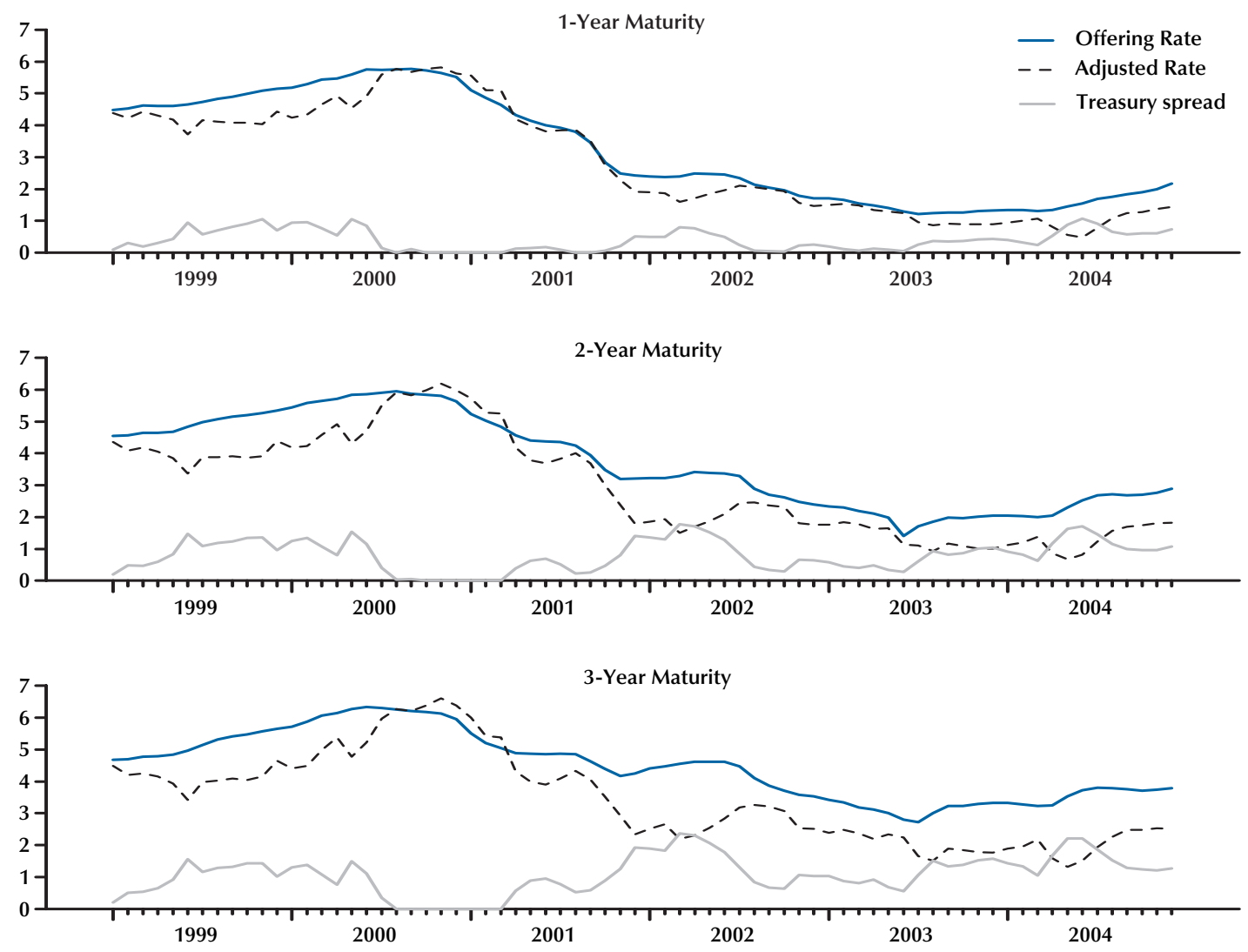
